\title{
Oral Bioavailability Enhancement and Anti-Fatigue Assessment of the Andrographolide Loaded Solid Dispersion
}

\author{
Ching-Chi Yen ${ }^{1}$, Yu-Kai Liang ${ }^{1}$, Chao-Pei Cheng ${ }^{1}$, Mei-Chich Hsu ${ }^{2,3,4}$ and Yu-Tse Wu ${ }^{1,3,5, *(D)}$ \\ 1 School of Pharmacy, Kaohsiung Medical University, Kaohsiung 807, Taiwan; \\ date0315@hotmail.com (C.-C.Y.); apccac1004@gmail.com (Y.-K.L.); hk810547@gmail.com (C.-P.C.) \\ 2 Department of Sports Medicine, Kaohsiung Medical University, Kaohsiung 807, Taiwan; \\ meichich@kmu.edu.tw \\ 3 Department of Medical Research, Kaohsiung Medical University Hospital, Kaohsiung 807, Taiwan \\ 4 Substance and Behavior Addiction Research Center, Kaohsiung Medical University, Kaohsiung 807, Taiwan \\ 5 Drug Development and Value Creation Research Center, Kaohsiung Medical University, Kaohsiung 807, \\ Taiwan \\ * Correspondence: ytwu@kmu.edu.tw; Tel.: +886-7-312-1101
}

Received: 3 March 2020; Accepted: 2 April 2020; Published: 4 April 2020

\begin{abstract}
Andrographolide (AG), a major diterpene lactone isolated from Andrographis paniculata (Burm. f.) Nees (Acanthaceae), possesses a wide spectrum of biological activities. However, its poor water solubility and low bioavailability limit its clinical application. Therefore, this study aimed to develop a solid dispersion (SD) formulation to increase the aqueous solubility and dissolution rate of AG. Different drug-polymer ratios were used to prepare various SDs. The optimized formulation was characterized for differential scanning calorimetry, Fourier transform infrared spectroscopy, and powder X-ray diffraction. The analysis indicated that the optimized SD enhanced AG solubility and dissolution rates by changing AG crystallinity to an amorphous state. The dissolution behaviors of the optimum SD composed of an AG-polyvinylpyrrolidone K30-Kolliphor EL ratio of 1:7:1 (w/w/w) resulted in the highest accumulated dissolution (approximately $80 \%$ ). Pharmacokinetic studies revealed that $C_{\max } /$ dose and the AUC/dose increased by 3.7-fold and 3.0-fold, respectively, compared with AG suspension. Furthermore, pretreatment using the optimized AG-SD significantly increased the swimming time to exhaustion by 1.7 -fold and decreased the plasma ammonia level by $71.5 \%$, compared with the vehicle group. In conclusion, the optimized AG-SD formulation appeared to effectively improve its dissolution rate and oral bioavailability. Moreover, the optimized AG-SD provides a promising treatment against physical fatigue.
\end{abstract}

Keywords: andrographolide; solid dispersion; oral bioavailability; anti-fatigue

\section{Introduction}

Andrographis paniculata (Burm. f.) Nees (Acanthaceae) is a medicinal plant native to south Asia and India. A. paniculata (AP) has a very bitter taste and is traditionally applied to ease internal heat, pain, and inflammation according to Chinese medicinal theory [1]. Andrographolide (AG) is a major diterpene lactone isolated from AP. Several studies have discovered the pharmacological activities of AG, and these findings demonstrated that AG might have potential for the alleviation of several diseases caused by the oxidative stress, and the main mechanisms include the activation of nuclear factor erythroid-2-related factor 2 and inhibition of nuclear factor- $\mathrm{kB}$ activation [2-4]. Recent studies have demonstrated that antioxidant supplementation may serve as a practical strategy for the alleviation of physical fatigue through modulating oxidative stress and inflammation status [5-7]. For 
example, the well-known anti-inflammatory curcumin and curcuminoids, which are hydroxycinnamic acid derivatives with polyphenolic rings, have demonstrated the ability to boost exhaustive swimming time and bust exercise fatigue-associated markers, including lactate, ammonia, and blood urea nitrogen (BUN) in mice [8]. In addition, one study enrolled 25 patients with multiple sclerosis and claimed that a 12-month supplementation of AP extract significantly reduced Fatigue Severity Scale scores compared with the placebo group [9]. AP has demonstrated positive effect in terms of relieving fatigue; however, the supplement period requires 12 months. Chen et al. [10] revealed that the oral bioavailability of AG was around $1.19 \%$ after a single administration $(50 \mathrm{mg} / \mathrm{kg})$, while our previous work has indicated the oral bioavailability of AG is approximate $0.3 \%$ after a single oral administration $(300 \mathrm{mg} / \mathrm{kg}$ ) [11]. Another study has found that the bioavailability of AG is $0.91 \%$ after a single 20 $\mathrm{mg} / \mathrm{kg}$ administration and only $0.21 \%$ at a higher dose of $200 \mathrm{mg} / \mathrm{kg}$ [12]. Lee et al. [13] noted that AG belongs to biopharmaceutical classification system (BCS) class II compound, which is sparingly soluble in water. Several studies also revealed that AG was a substrate of P-glycoprotein (P-gp) $[14,15]$. Therefore, the low solubility $(0.07 \mathrm{mg} / \mathrm{mL})$ and the efflux transport by P-gp may lead to the poor oral absorption of AG. Thus, proposing a practical delivery system for increasing the oral bioavailability of AG remains crucial for the successful clinical and health application of this active component.

Various formulations have been proposed to improve the solubility, dissolution, and bioavailability of AG. These formulation approaches for AG included solid dispersion (SD) [16-20], liposomes [21], niosomes [22], and solid lipid nanoparticles (SLN) [23] and focused on in vitro characterization for delivery systems and assessing their effects on diverse cell models. The inclusion complex composed of AG and hydroxypropyl- $\beta$-cyclodextrin has been proposed to elevate the bioavailability of AG by 1.6-fold [14]. In addition, a pH-sensitive nanoparticle has been designed to improve the oral bioavailability of AG by approximately 2.2 times [24]. SLN has been proposed for enhancing the oral bioavailability of AG by approximately 2.41 times [25]. A liquid self-microemulsifying drug delivery system containing AG extract, Capryol 90, Kolliphor RH 40, and Labrasol has been developed, and the results revealed a 15-fold enhancement of absorption compared with that of the AG extract suspension [26]. However, a high emulsifier concentration in the formulation might result in gastrointestinal irritation, and stability is also crucial to ensure its feasibility.

The SD technique features as one of the more fascinating among solubilization methods because the combination of the active components and polymers with various functions can lead to significant enhancements in solubility, disintegration, and dissolution of active components [27]. Bothiraja et al. [16] demonstrated the utility of SD to improve the pharmaceutical properties of AG using polyvinylpyrrolidone (PVP) K-30 as a carrier. Zhao et al. [17] prepared AG-SD by spray-drying and vacuum-drying methods with different grafted polyethylene glycol (PEG) as carrier material. Zhang et al. [18] also confirmed that the feasibility of silica as a carrier of SD to enhance the dissolution of AG. However, pharmacokinetic data for the above systems are lacking; thus, their effects on the absorption of AG cannot be confirmed. Nanocrystal-based SD prepared by Ma et al. [19] and AG-solid self-nanodispersion delivery system developed by $\mathrm{Xu}$ et al. [20] have exhibited a fast dissolution rate and significantly improved the bioavailability of AG. Nevertheless, several steps containing homogenization and spray-drying technology render the optimization of their preparation process complicated and time-consuming. Thus, identifying a suitable drug delivery system with a relatively easy way for increasing the oral bioavailability of AG remains a task of great interest. Fitriani et al. [28] reported that SD can enhance the solubility of usnic acid and its antioxidant activity due to the improvement of usnic acid's solubility. Nadal et al. [29] also proved that SD could retain the antioxidant activity of ferulic acid and further improved its in vivo anti-platelet effect. In addition, our pervious study has revealed that the anti-fatigue efficiency of resveratrol can be enhanced through dosage form modification [30]. Furthermore, there has been relatively little research conducted on anti-fatigue pharmacological effects after AG supplement. When composition parameters, including polymer types, molecular weight, and percentage within formulation, as well as the active component's crystalline-amorphous states, are carefully manipulated, oral bioavailability improves considerably [31]. 
In the current study, we selected PVP and PEG with different average molecular weights to prepare an AG-loaded SD delivery system. The proposed optimized formulation was characterized in terms of its physicochemical properties, oral bioavailability, and potential anti-fatigue effects.

\section{Results and Discussion}

\subsection{Formulation Screening by Dissolution}

AG dissolution profiles, physical mixtures, and AG-loaded SDs were evaluated in $0.1 \mathrm{~N} \mathrm{HCl}(\mathrm{pH}$ 1.2) medium, as depicted in Figure 1. Dissolution performance parameters, including cumulative percentage release in $5 \mathrm{~min}\left(\mathrm{Q}_{5 \mathrm{~min}}\right)$, cumulative percentage release in $120 \mathrm{~min}\left(\mathrm{Q}_{120 \mathrm{~min}}\right)$, dissolution efficiency (D.E.), and the time required to reach $70 \%$ release $\left(t_{70} \%\right)$, are summarized in Table 1 . From the dissolution results (Figure 1e), AG demonstrated a relatively low accumulated dissolution of approximately $35 \%$. $\mathrm{Q}_{120 \mathrm{~min}}$ obviously increased to more than $75 \%$ when formulated as $\mathrm{SD}$, and the physical mixture group (F20) displayed a $\mathrm{Q}_{120 \mathrm{~min}}$ of approximately $53 \%$. AG is recognized as a BCS class II compound [13], which means dissolution in the gastrointestinal tract is the rate-limiting step for oral absorption. Therefore, enhancing dissolution is crucial for efficiently improving the oral bioavailability of AG. Hydrophilic polymers, such as PEG and PVP, have been commonly used as carriers for SD because of their low cost, sufficient water solubility, and ability to transform active ingredients into amorphous states [32]. The dissolution profile revealed that the SD made of PVP generally exhibited a quicker release than SD made of PEG 6000 (Figure 1a). When the AG/polymer ratio is greater than 1:3 in the formulations of PVP K15 (Figure 1b) and K30 (Figure 1c), the average values of $\mathrm{Q}_{5 \mathrm{~min}}$ could surpass $70 \%$. However, the dissolution pattern of AG from PVP K90 SD (Figure 1d) was slower $\left(\mathrm{Q}_{5 \mathrm{~min}}<63.3 \%\right)$. This phenomenon may have resulted from the elevated local viscosity caused by PVP K90, which restricts the diffusion near the boundary layer of SD [33]. We selected F13 (AG/PVP K30 1:7, w/w) for further investigation because it displayed the highest $Q_{5 \mathrm{~min}}$, $\mathrm{Q}_{120 \mathrm{~min}}$, and D.E. The effects of surfactant addition on dissolution were also examined, and the addition of Kolliphor EL brought the accumulated dissolution to approximately $80 \%$. Finally, we chose F19 (AG/PVP K30/Kolliphor EL = 1:7:1, w/w/w) as the optimized formulation. Incorporation of a surfactant in a SD to improve the dissolution rate is also described in other studies $[34,35]$. These results may be explained as the inclusion of surfactants in the formulation containing a polymeric carrier might help to prevent precipitation and/or protect a fine crystalline precipitate from agglomeration into much larger hydrophobic particles [36]. 
(a)

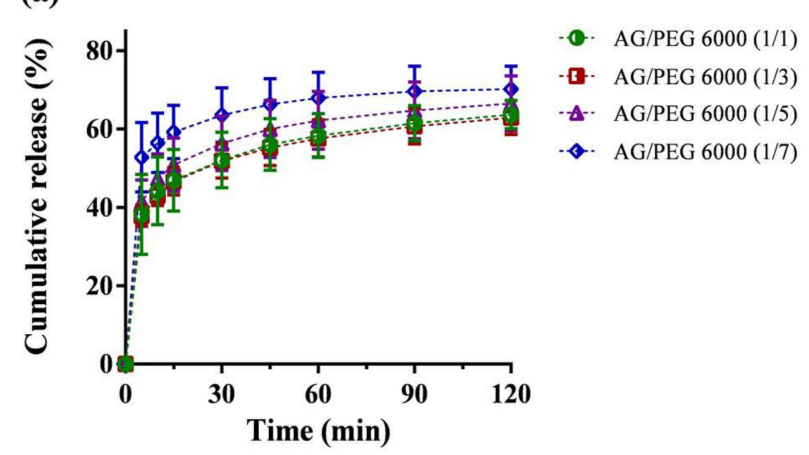

(b)

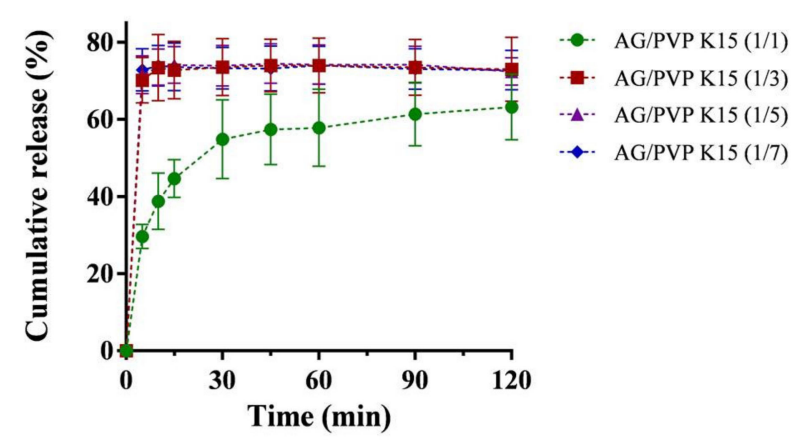

(c)

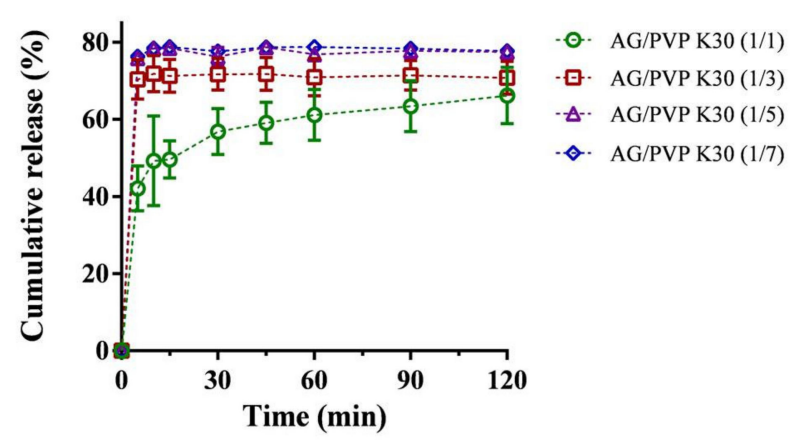

(d)

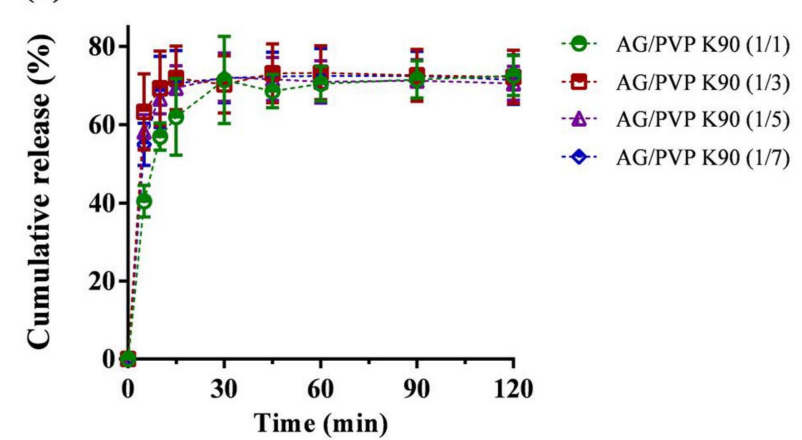

(e)

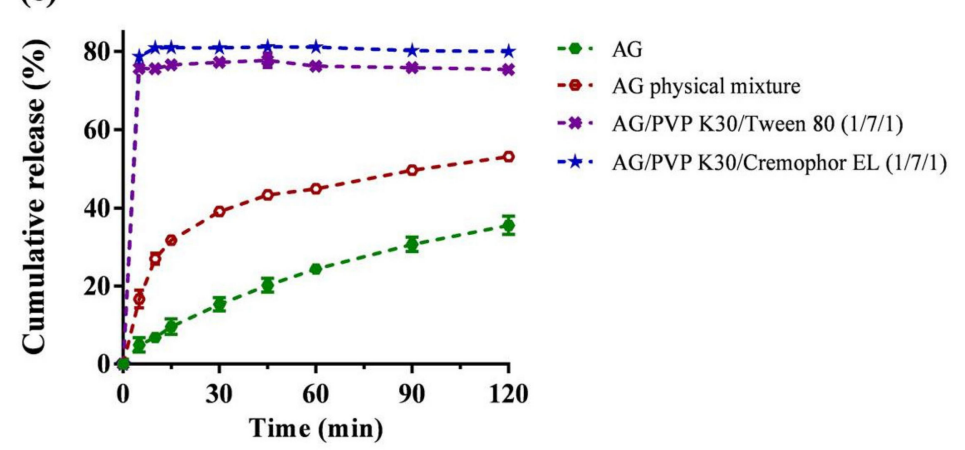

Figure 1. Dissolution profiles of andrographolide (AG) prepared using: (a) PEG 6000; (b) polyvinylpyrrolidone (PVP) K15; (c) PVP K30; (d) PVP K90; and (e) PVP K30 containing Tween 80 or Kolliphor EL as surfactant carrier. Data are presented as mean \pm standard deviation $(n=3$ for each group). 
Table 1. Ingredients, weight ratios, and dissolution performance of andrographolide (AG) and AG-loaded solid dispersion formulations.

\begin{tabular}{|c|c|c|c|c|c|c|}
\hline \multirow{2}{*}{ Formulation } & \multirow{2}{*}{ Ingredients } & \multirow{2}{*}{ Weight Ratio $(w / w)$} & \multicolumn{4}{|c|}{ Dissolution } \\
\hline & & & $\mathbf{Q}_{5 \min }$ & $\mathrm{Q}_{120 \min }$ & D.E. & $t_{70 \%}(\min )$ \\
\hline 1 & AG & NA & $4.9 \pm 1.8$ & $35.6 \pm 2.3$ & $22.4 \pm 1.7$ & NA \\
\hline 2 & AG, PEG 6000 & $1 / 1$ & $38.2 \pm 10.2^{*}$ & $63.7 \pm 3.6^{*}$ & $55.1 \pm 5.8^{*}$ & NA \\
\hline 3 & AG, PEG 6000 & $1 / 3$ & $37.9 \pm 2.7^{*}$ & $62.9 \pm 4.3^{*}$ & $54.5 \pm 4.2^{*}$ & NA \\
\hline 4 & AG, PEG 6000 & $1 / 5$ & $41.5 \pm 5.6^{*}$ & $66.6 \pm 7.0^{*}$ & $58.7 \pm 6.9^{*}$ & NA \\
\hline 5 & AG, PEG 6000 & $1 / 7$ & $52.8 \pm 8.9^{*}$ & $70.3 \pm 5.9^{*}$ & $64.7 \pm 6.5^{*}$ & 120 \\
\hline 6 & AG, PVP K15 & $1 / 1$ & $29.6 \pm 3.1^{*}$ & $63.2 \pm 8.6^{*}$ & $54.7 \pm 7.8^{*}$ & NA \\
\hline 7 & AG, PVP K15 & $1 / 3$ & $70.2 \pm 5.9^{*}$ & $73.0 \pm 8.3^{*}$ & $71.9 \pm 8.2^{*}$ & 5 \\
\hline 8 & AG, PVP K15 & $1 / 5$ & $71.6 \pm 4.9^{*}$ & $72.4 \pm 3.6^{*}$ & $72.3 \pm 4.6^{*}$ & 5 \\
\hline 9 & AG, PVP K15 & $1 / 7$ & $72.9 \pm 5.5^{*}$ & $72.8 \pm 5.1^{*}$ & $71.8 \pm 5.2^{*}$ & 5 \\
\hline 10 & AG, PVP K30 & $1 / 1$ & $42.1 \pm 5.8^{*}$ & $66.2 \pm 7.3^{*}$ & $58.0 \pm 6.2^{*}$ & NA \\
\hline 11 & AG, PVP K30 & $1 / 3$ & $70.4 \pm 5.1^{*}$ & $70.8 \pm 4.3^{*}$ & $69.8 \pm 4.2^{*}$ & 5 \\
\hline 12 & AG, PVP K30 & $1 / 5$ & $75.9 \pm 0.2^{*}$ & $77.5 \pm 0.1^{*}$ & $75.9 \pm 0.7^{*}$ & 5 \\
\hline 13 & AG, PVP K30 & $1 / 7$ & $76.3 \pm 0.9^{*}$ & $77.8 \pm 1.4^{*}$ & $77.8 \pm 1.7^{*}$ & 5 \\
\hline 14 & AG, PVP K90 & $1 / 1$ & $40.5 \pm 4.1^{*}$ & $72.5 \pm 5.1^{*}$ & $66.9 \pm 5.3^{*}$ & 30 \\
\hline 15 & AG, PVP K90 & $1 / 3$ & $63.3 \pm 9.7^{*}$ & $72.2 \pm 6.9^{*}$ & $70.3 \pm 7.0^{*}$ & 15 \\
\hline 16 & AG, PVP K90 & $1 / 5$ & $58.3 \pm 4.3^{*}$ & $70.6 \pm 4.4^{*}$ & $68.9 \pm 5.1^{*}$ & 30 \\
\hline 18 & AG, PVP K30, Tween 80 & $1 / 7 / 1$ & $75.7 \pm 1.2^{*}$ & $75.4 \pm 0.6^{*}$ & $74.8 \pm 0.1^{*}$ & 5 \\
\hline 19 & AG, PVP K30, Kolliphor EL & $1 / 7 / 1$ & $78.7 \pm 0.1 *$ & $80.0 \pm 0.7^{*}$ & $78.9 \pm 0.5^{*}$ & 5 \\
\hline 20 & Physical mixture (AG, PVP K30, Kolliphor EL) & $1 / 7 / 1$ & $16.7 \pm 2.3^{*}$ & $53.2 \pm 0.2^{*}$ & $43.2 \pm 0.5^{*}$ & NA \\
\hline
\end{tabular}

PVP, polyvinylpyrrolidone; PEG, polyethylene glycol; $\mathrm{Q}_{5 \mathrm{~min}}$, cumulative percentage release in 5 min; $\mathrm{Q}_{120 \mathrm{~min}}$, cumulative percentage release in 120 min; $\mathrm{D} . \mathrm{E}$. , dissolution efficiency; $\mathrm{t} 70 \%$,
the time required to reach $70 \%$ release; NA, not applicable. The results are presented as mean + standard deviation $\left(n=3\right.$ for each formulation); ${ }^{*} p<0.05$, compared with $\mathrm{AG}$ group 


\subsection{Differential Scanning Calorimetric Analysis}

The differential scanning calorimetry (DSC) analysis was used to assess the amorphous state of AG. Pure AG displayed an endothermic peak at $233^{\circ} \mathrm{C}$ (Figure 2a), which corresponded to the melting point of AG [37]. Figure 2b,c showed the thermograms of PVP K30 and Kolliphor EL. For both SD formulations (Figure 2e,g), the endothermic peak of AG at approximately $233^{\circ} \mathrm{C}$ disappeared and no other endothermic peaks were observed, implying AG mainly existed in amorphous state in the solid. AG prepared by physical mixture combinations (Figure $2 \mathrm{~d}, \mathrm{f}$ ) also displayed a disappearance of sharp AG endothermic peak; this phenomenon may be caused by the dilution of AG sample via the preparation process. It could not be proved that $A G$ was under its amorphous form. This was further confirmed by powder X-ray diffraction (XRPD) study.

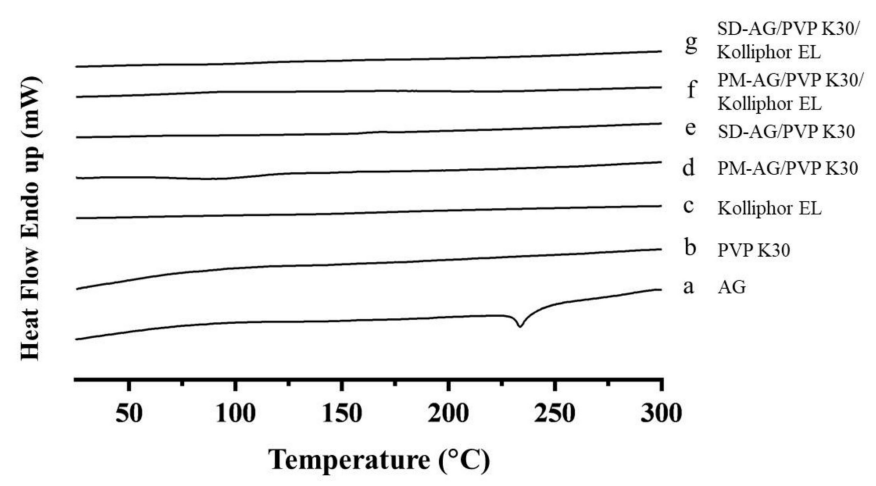

Figure 2. Differential scanning calorimetry spectrum of: (a) andrographolide (AG); (b) PVP K30; (c) Kolliphor EL; (d) physical mixture (PM)-AG/PVP K30 (1:7, w/w); (e) solid dispersion (SD)-AG/PVP K30 (1:7, w/w); (f) PM-AG/PVP K30/Kolliphor EL (1:7:1, w/w/w); and (g) SD-AG/PVP K30/Kolliphor EL $(1: 7: 1, w / w / w)$.

\subsection{Powder X-Ray Diffraction Analysis}

PXRD patterns of pure AG, PVP K30, physical mixtures, and AG-loaded SDs are illustrated in Figure 3. As depicted in Figure 3a, AG's diffraction pattern was highly crystalline in its natural state, as indicated by the numerous peaks. The results resemble those of Ma et al. [19]. The powdered PVP K30 was amorphous where no prominent peaks were detected (Figure 3b). The physical mixtures displayed diffraction patterns similar to those of pure AG, indicating that the crystallinity of AG was not affected by the process utilized to obtain it (Figure 3c,e). However, the powder X-ray diffraction patterns of the SDs suggested that AG was no longer present in its crystalline form in the SDs but existed in an amorphous state (Figure $3 \mathrm{~d}, \mathrm{f}$ ). These results confirmed that AG was present in amorphous form within the SDs.

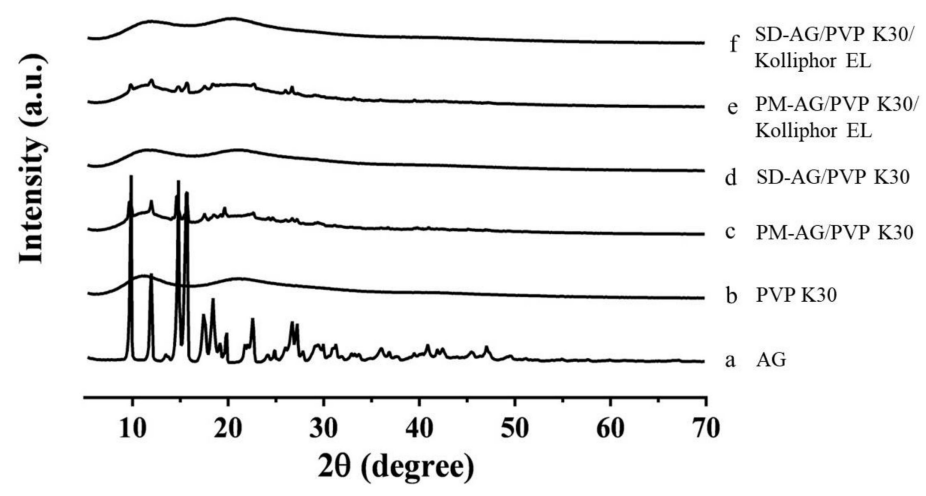

Figure 3. Powder x-ray diffraction patterns of: (a) andrographolide (AG); (b) PVP K30; (c) physical mixture (PM)-AG/PVP K30 (1:7, w/w); (d) solid dispersion (SD)-AG/PVP K30 (1:7, w/w); (e) PM-AG/PVP K30/Kolliphor EL (1:7:1, w/w/w); and (f) SD-AG/PVP K30/Kolliphor EL (1:7:1, w/w/w). 


\subsection{Fourier Transform Infrared Spectroscopy}

The Fourier transform infrared spectroscopy (FT-IR) spectroscopy was applied to evaluate the possible chemical interactions between AG and PVP. AG demonstrated a typical C=O band at 1674.6 $\mathrm{cm}^{-1}$ and an $\mathrm{OH}$ stretch at $3397.1 \mathrm{~cm}^{-1}$ (Figure $4 \mathrm{a}$ ), which corresponded to the results of a previous report [20]. The characteristic bands of PVP appeared approximately at 1662.3 and $2950.4 \mathrm{~cm}^{-1}$ (Figure $4 b$ ), which corresponded to the pyrrole moiety and the C-H stretch, respectively [38]. Spectra characteristic band from 1550 to $1650 \mathrm{~cm}^{-1}$, which is typically observed for carboxylate anions, was not observed in the purified Kolliphor EL (Figure 4c) [39]. The FTIR spectra of physical mixtures (Figure 4d,f) seemed to be only a summation of AG and PVP K30 spectra, implying a lack of chemical interaction. For the formulations of $\mathrm{SD}$, the $\mathrm{OH}$ stretch at $3397.1 \mathrm{~cm}^{-1}$ disappeared, and the $\mathrm{C}=\mathrm{O}$ band at $1674.6 \mathrm{~cm}^{-1}$ shifted to 1660.3 (Figure $4 \mathrm{e}$ ) and $1659.3 \mathrm{~cm}^{-1}$ (Figure $4 \mathrm{~g}$ ). These results could be explained by intermolecular interactions (e.g., hydrogen bonding), suggesting that the crystalline form of AG was transformed into an amorphous state [40].

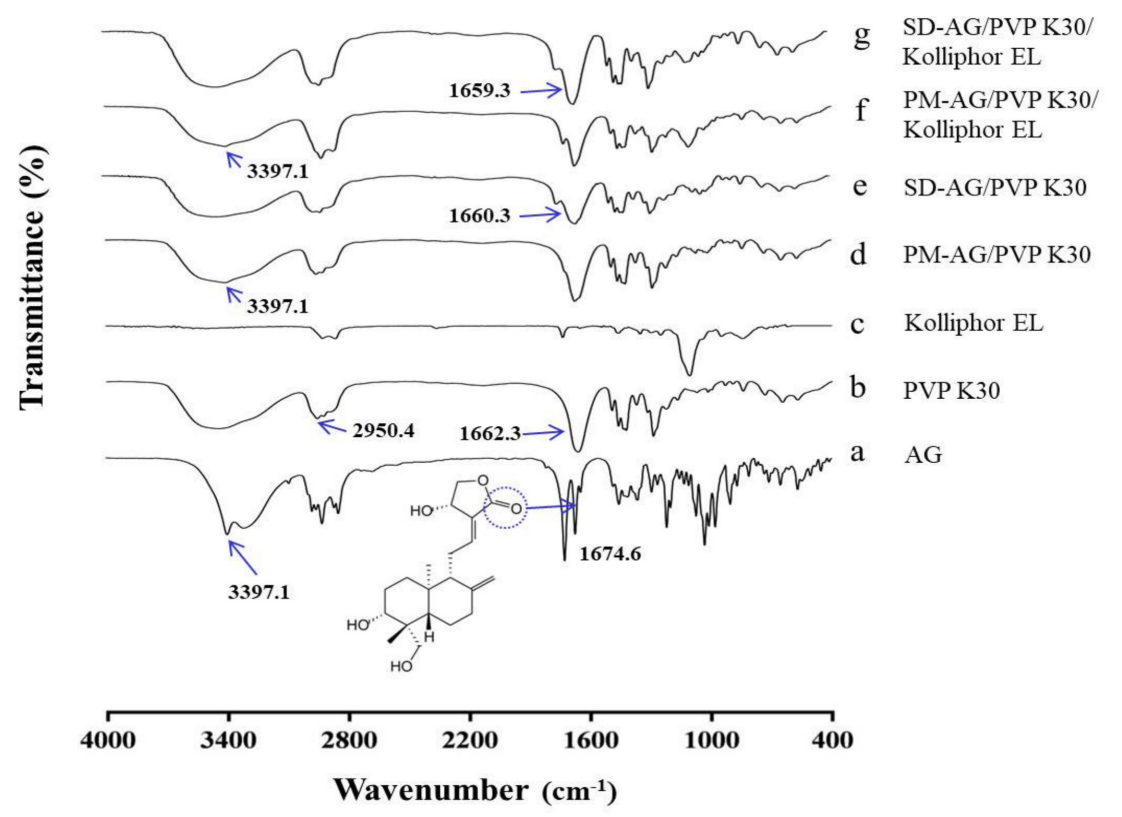

Figure 4. Fourier-transform infrared spectroscopy spectrums of: (a) andrographolide (AG); (b) PVP K30; (c) Kolliphor EL; (d) physical mixture (PM)-AG/PVP K30 (1:7, w/w); (e) solid dispersion (SD)-AG/PVP K30 (1:7, w/w); (f) PM-AG/PVP K30/Kolliphor EL (1:7:1, w/w/w); and (g) SD-AG/PVP K30/Kolliphor EL $(1: 7: 1, w / w / w)$.

\subsection{Ex vivo Permeability}

The concentrations of AG absorbed from the suspension and the optimized SD through intestinal segments are depicted in Figure 5. The results indicate that the AG concentrations in the duodenum, jejunum, and ileum were $2.55 \pm 0.49,2.56 \pm 0.36$, and $2.18 \pm 0.45 \mu \mathrm{g} / \mathrm{mL}$, respectively, and the optimized AG-loaded SD composed of AG/PVPK30/Kolliphor EL (1:7:1, w/w/w) significantly enhanced the penetration of AG at intestinal segments. The jejunum proved to be the best region for AG absorption in SD, which attained a concentration approximately 2.7 times higher than that of the unformulated AG suspension. The results suggest that the optimized formulation improved dissolution performance translated to higher intestinal permeability of AG. 


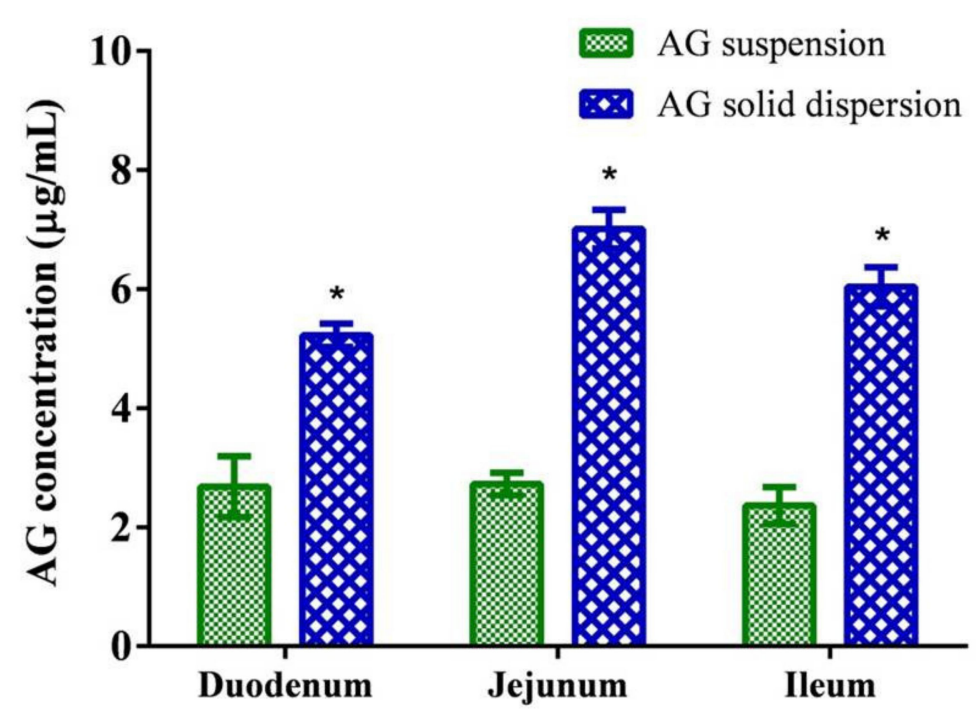

Figure 5. Permeability test of andrographolide (AG) suspension and optimized AG-loaded solid dispersion. Data are presented as mean \pm standard deviation ( $n=3$ for each group). * Indicates significant difference compared to the AG suspension group $(p<0.05)$.

\subsection{Oral Bioavailability Assessment}

The plasma concentration-time curve and pharmacokinetic parameters of AG after oral administration of the AG suspension ( $300 \mathrm{mg} / \mathrm{kg}$ ) and the optimized AG-loaded SD (100 mg/kg,) in rats are depicted in Figure 6 and Table 2, respectively. The maximum plasma concentration $\left(C_{\max }\right) /$ dose and the area under the plasma concentration-time curve (AUC)/dose attained after administration of the AG-loaded SD were $2.5 \pm 0.6 \mathrm{rat} \mathrm{ng} / \mathrm{mL}$ and $9.3 \pm 1.8 \mathrm{~h} \mathrm{rat} \mathrm{ng} / \mathrm{mL}$, which were 3.7 -fold and 3.0-fold higher than those of the oral AG suspension, respectively. The relative bioavailability was determined to be $297.7 \%$. These data provide strong evidence for improvement in AG absorption under optimized AG-loaded SD. AG possesses low solubility and encounters extensive metabolism together with efflux transportation by P-gp in the intestinal tract, which contributes to limited oral absorption. A higher dose of $300 \mathrm{mg} / \mathrm{kg}$ was therefore selected to appropriately reflect the pharmacokinetic profile of AG suspension. According to a previous study [41], Kolliphor EL, which might be P-gp specific, could inhibit the function of P-gp, thereby increasing the intestinal absorption of various drugs that are secreted by a P-gp-mediated efflux system in the intestine. Therefore, the use of Kolliphor EL in the SD might prevent the efflux of AG by P-gp to increase AG oral absorption.

Table 2. Pharmacokinetic parameters of andrographolide (AG) after oral administration of AG suspension, and AG-loaded solid dispersion in rats.

\begin{tabular}{cccc}
\hline Parameters & Units & $\begin{array}{c}\text { AG Suspension } \\
\mathbf{( 3 0 0 ~} \mathbf{~ m g} / \mathbf{k g}, \mathbf{p . o .})\end{array}$ & $\begin{array}{c}\text { AG solid Dispersion } \\
\mathbf{( 1 0 0 ~} \mathbf{~ m g} / \mathbf{k g}, \mathbf{p . o} .)\end{array}$ \\
\hline$T_{\max }$ & $\mathrm{h}$ & $2.1 \pm 1.8$ & $0.4 \pm 0.3$ \\
$t_{1 / 2}$ & $\mathrm{~h}$ & $7.1 \pm 3.7$ & $7.0 \pm 3.1$ \\
$C_{\max }$ & $\mathrm{ng} / \mathrm{mL}$ & $206.6 \pm 57.6$ & $254.0 \pm 59.7$ \\
$\mathrm{AUC}_{0-\mathrm{t}}$ & $\mathrm{h} \mathrm{ng} / \mathrm{mL}$ & $935.3 \pm 130.3$ & $928.2 \pm 181.1$ \\
$C_{\max } /$ dose & $(\mathrm{ng} / \mathrm{mL}) /(\mathrm{mg} / \mathrm{kg})$ & $0.7 \pm 0.2$ & $2.5 \pm 0.6^{*}$ \\
$\mathrm{AUC}_{0-\mathrm{t}} /$ dose & $(\mathrm{h} \mathrm{ng} / \mathrm{mL}) /(\mathrm{mg} / \mathrm{kg})$ & $3.1 \pm 0.4$ & $9.3 \pm 1.8^{*}$ \\
Relative bioavailability & $\%$ & - & 297.7 \\
\hline
\end{tabular}

$T_{\max }$, time of occurrence for maximum AG concentration; $C_{\max }$, maximum concentration of AG; $t_{1 / 2}$, AG half-life; $\mathrm{AUC}_{0-\mathrm{t}}, \mathrm{AG}$ area under the plasma concentration-time curve from zero $(0) \mathrm{h}$ to time $(\mathrm{t}) .{ }^{*}$ Significantly different compared to AG suspension group $(p<0.05)$. Data are expressed as mean \pm standard deviation $(n=5$ for each group). 


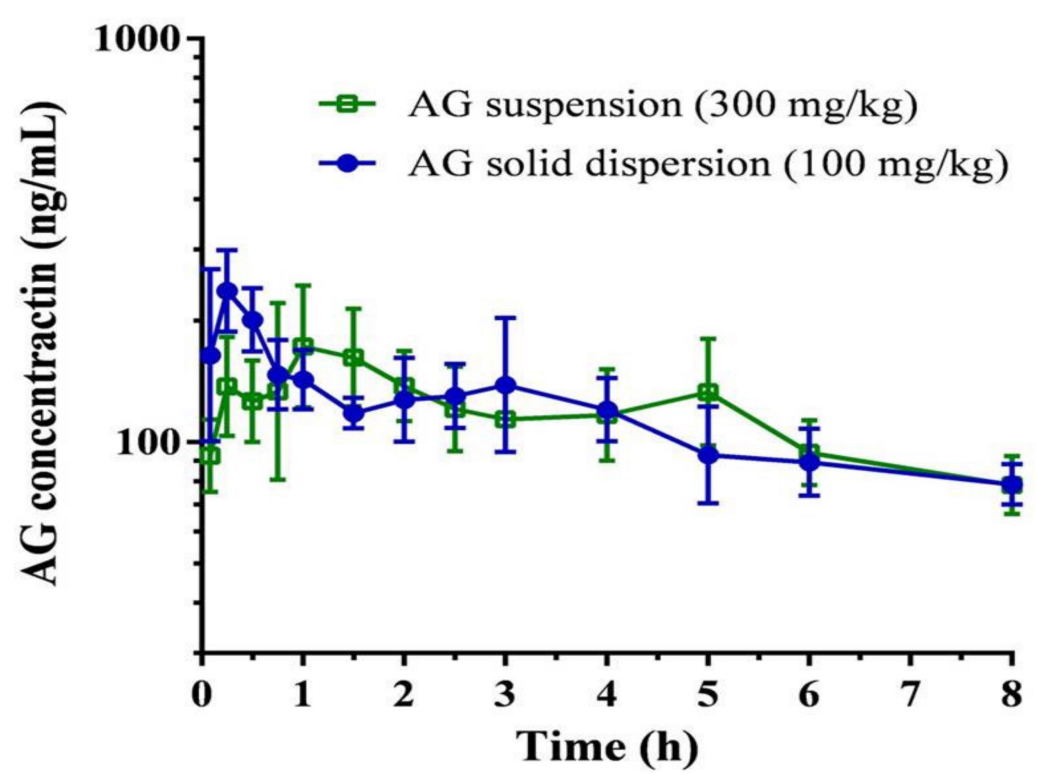

Figure 6. Plasma concentration-time curve of andrographolide (AG) after oral administration of AG suspension and optimized AG-loaded solid dispersion in rats. Data are expressed as mean \pm standard deviation ( $n=5$ for each group).

\subsection{Anti-Fatigue Effects}

\subsubsection{Physical Performance Test}

The physical performance tests involved a forelimb grip test and exhaustive swimming test. Grip strength tests can be used to assess motor-associated coordination and adaption in neurological studies and reflect the overall health of the musculoskeletal system. Grip strength in the vehicle, AG suspension, and AG-loaded SD group were 715.2 $\pm 72.7,713.8 \pm 69.2$, and $824.4 \pm 45.8$ g, respectively (Figure 7a). We discovered no significant differences in grip strength among the three treatment groups. The exercise endurance test is a major method in evaluating anti-fatigue treatment. The exhaustive swimming time in the vehicle, AG suspension, and AG-loaded SD groups were 10.6 $\pm 1.6,10.5 \pm 1.7$, and $17.8 \pm 1.6 \mathrm{~min}$, respectively (Figure $7 \mathrm{~b}$ ). Our data indicate that pretreatment with AG suspension did not increase the exhaustive swimming time, which might be explained by the low AG absorption. By contrast, the exhaustive swimming time was prolonged by 1.7-fold with AG-loaded SD compared with that in the vehicle group.

(a)

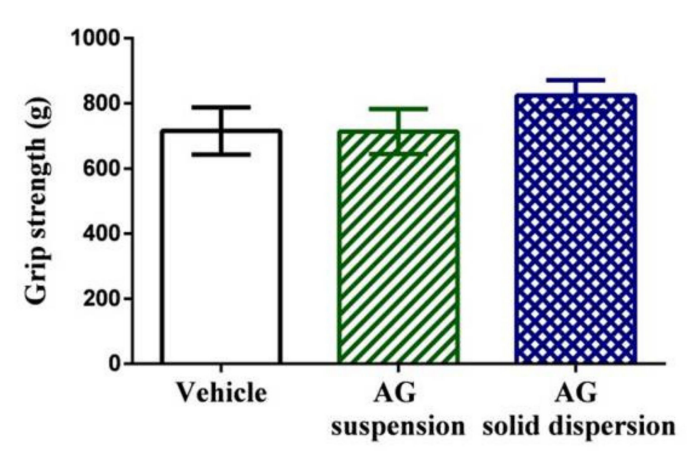

(b)

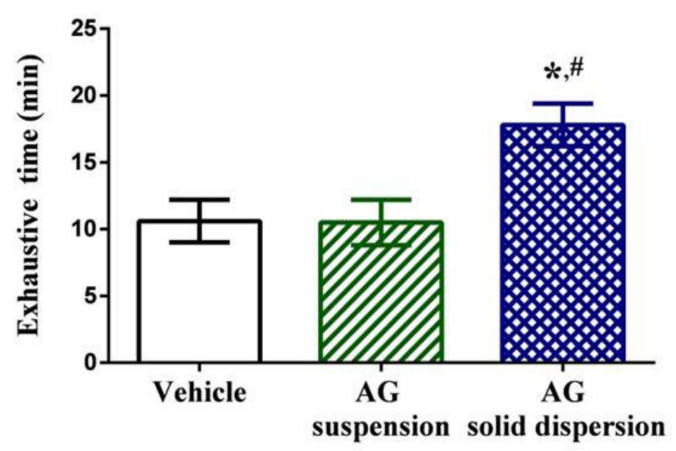

Figure 7. Effect of andrographolide (AG) on: (a) forelimb grip test; and (b) exhaustive swimming test. Data are expressed as mean \pm standard deviation $\left(n=5\right.$ for each group). ${ }^{*}$ Indicates significant difference compared to vehicle group $(p<0.05)$. \# Indicates significant difference compared to AG suspension group $(p<0.05)$. 
Fatigue can be defined as a state of weariness that is either physical or mental, which is caused by exertion and can lead to deterioration in physical performance [42]. According to previous studies, oxidative stress and inflammatory mediators could be possible weighty mechanisms for physical fatigue because the accumulation of reactive oxygen species during exercise processes raises oxidative stress and leads to oxidative damage on mitochondria and muscle contractile protein [43]. As an antioxidant, AP has proven its ability to relieve fatigue; however, the pretreatment protocols are time-consuming, possibly due to its low bioavailability. As a result, the optimized AG-loaded SD overcomes the shortcomings of time-consuming AG pretreatment due to the enhancement of AG oral bioavailability. Moreover, the anti-fatigue potential of AG-loaded SD has also been demonstrated.

\subsubsection{Lactate Production and Clearance Ratio}

Figure $8 \mathrm{a}, \mathrm{b}$ displays lactate production and clearance ratios during high-intensity swimming. Anaerobic glycolysis is the transformation of glucose to lactate when limited amounts of oxygen are available. During high-intensity exercise, the intramuscular accumulation of lactic acid has long been considered one of the most crucial factors in fatigue [44]. The results show that the lactate production and clearance ratios among the three groups did not show significant difference.

(a)

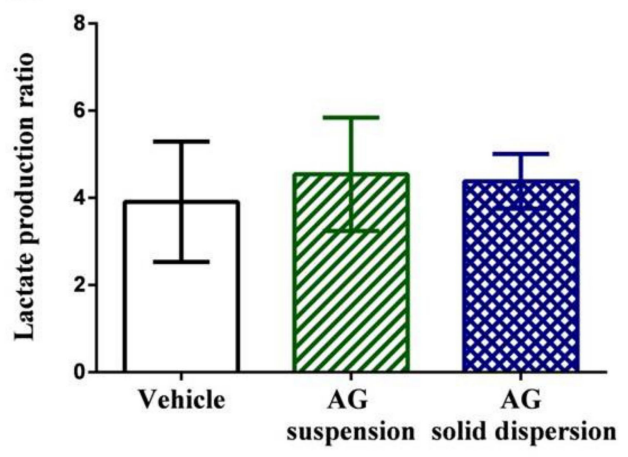

(b)

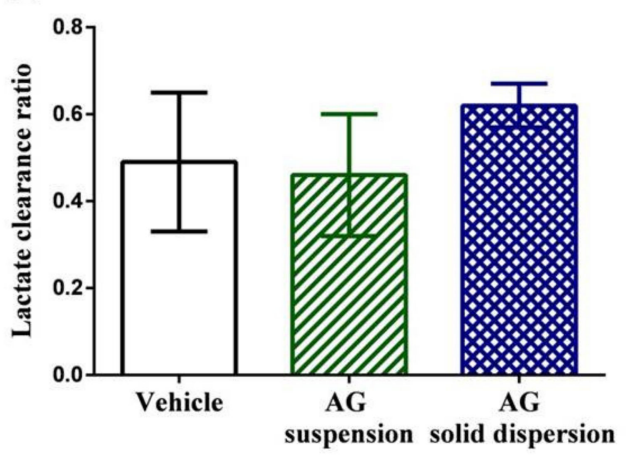

Figure 8. Effect of andrographolide (AG) on: (a) lactate production ratio; and (b) lactate clearance ratio. Data are expressed as mean \pm standard deviation ( $n=5$ for each group). Lactate production

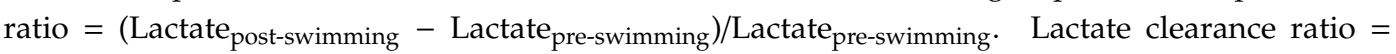
(Lactate post-swimming $_{\text {- Lactate }} 30$ min later after post-swimming $) /$ Lactate post-swimming $_{\text {. }}$

\subsubsection{Fatigue-Related Indicator Determination}

Biochemical indicators containing plasma ammonia $\left(\mathrm{NH}_{3}\right)$, blood urea nitrogen $(\mathrm{BUN})$, creatine phosphokinase (CPK), and glucose are normally used to assess the status of muscle fatigue after exercise [45]. Plasma ammonia levels in the vehicle, AG suspension, and AG-loaded SD groups were $459 \pm 258,234 \pm 32$, and $131 \pm 33 \mu \mathrm{mol} / \mathrm{L}$, respectively (Figure 9a). Ammonia, a metabolite of protein and amino acid, is linked to neuromuscular fatigue during resistance training and affects continual coordinated activity in critical regions of the central nervous system [46,47]. The plasma ammonia levels in rats were significantly lower (by 71.5\%) after pretreatment with the AG-loaded SD compared with those in the vehicle group. Urea nitrogen is the metabolic outcome of protein and amino acids. When carbohydrates and fats cannot provide sufficient energy to the body, BUN levels increase because of strong catabolic metabolism form protein and amino acids. Previous studies have revealed that BUN may have a positive correlation with exercise tolerance [48,49]. Therefore, BUN is another crucial biochemical parameter related to fatigue. The results reveal that the BUN level decreased by $10.7 \%$ after AG-loaded SD treatment; however, the values did not differ in both groups (Figure 9b). CPK is a clinical biomarker for muscle damage [50], and no significant differences in the activity of CPK among the three treated groups were observed, suggesting the inhibition of muscle damage after pretreatment with AG was not obvious (Figure 9c). Efficient utilization of glucose is an important 
performance maintenance index during exercise [51]. The results reveal that serum glucose level was lowered by $17.4 \%$ and $13.9 \%$ with AG suspension and AG-loaded SD treatments compared with the vehicle treatment group after exercise (Figure 9d). Although the values of serum glucose did not statistically differ among the three groups, AG appears to have the potential to make tissues more efficiently use glucose.

(a)

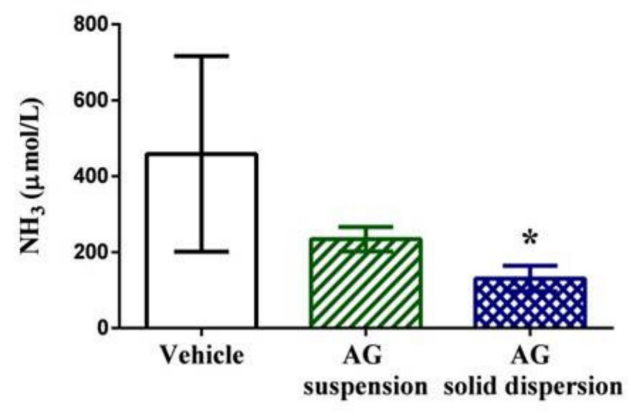

(c)

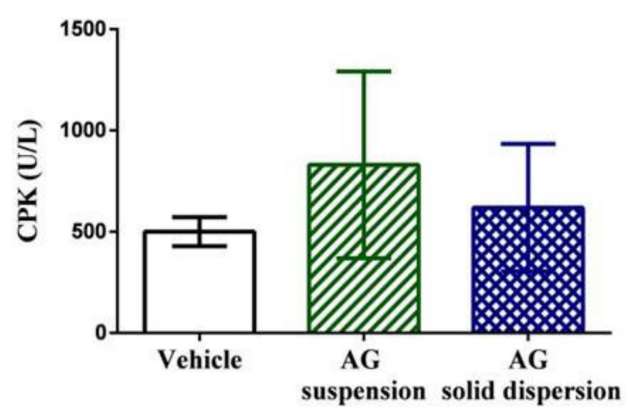

(b)

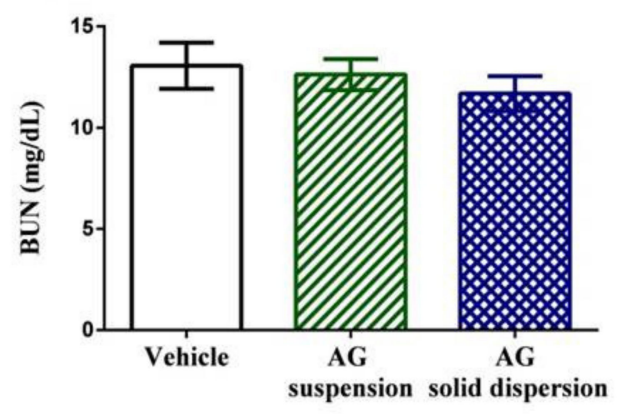

(d)

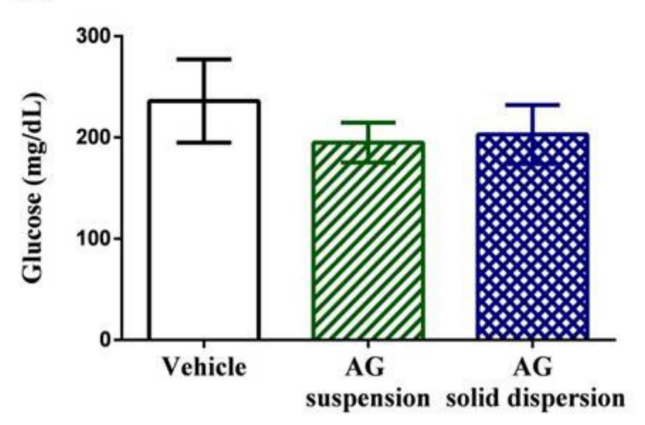

Figure 9. Effect of andrographolide (AG) on: serum (a) ammonia; (b) blood urea nitrogen (BUN); (c) creatine phosphokinase (CPK); and (d) glucose levels after swimming challenge. Data are expressed as mean \pm standard deviation ( $n=5$ for each group). ${ }^{*}$ Indicates significant difference compared to vehicle group $(p<0.05)$.

Supplementation with antioxidant nutrients could prevent exercise-induced oxidative damage and lactate accumulation [52,53]. As an antioxidant and owning anti-inflammatory activity, we hypothesized AG may serve as a practical strategy for the alleviation of physical fatigue via modulating oxidative stress and inflammation status. Our study indicated that AG-loaded SD supplements could prolong the exhaustive swimming time. To identify the evidence most relevant to the mechanism, exercise-induced fatigue-related parameters, such as lactate, ammonia, BUN, CPK, and glucose levels, were investigated. The results show that the improvement of exercise performance in rat might be explicated by reducing blood ammonia. According to a previous study, oxidative stress is an evolving concept in the pathogenesis of ammonia neurotoxicity [54]. As an antioxidant agent, AG could reduce blood ammonia, especially in SD forms that could enhance the bioavailability of AG.

\subsubsection{Tissue Glycogen Determination}

Muscular glycogen levels in the vehicle, AG suspension, and AG-loaded SD groups were $0.5 \pm$ $0.3,0.2 \pm 0.13$, and $0.2 \pm 0.1 \mathrm{mg} / \mathrm{g}$, respectively (Figure 10a). We did not find any significant difference in the muscular glycogen contents among groups. By contrast, hepatic glycogen levels in the vehicle, AG suspension, and AG-loaded SD groups were $1.7 \pm 0.8,5.0 \pm 1.0$, and $4.5 \pm 1.5 \mathrm{mg} / \mathrm{g}$, respectively (Figure 10b). Energy expenditure and deficiency can lead to physical fatigue during exercise. Therefore, energy storage and supply are another crucial factor related to exercise performance [55]. In this study, we discovered that hepatic glycogen level was significantly increased by 2.9-fold and 2.6-fold with AG 
suspension and AG-loaded SD treatments. The same phenomenon was also observed by Subramanian et al. [56]. They revealed that treatment with AG and its extract for 21 days increased glucokinase levels, which is the first step for both glycogen and glycolysis synthesis in the liver. The synthesis of glucokinase is highly sensitive to oxidative stress. As an antioxidant agent, AG increases liver glycogen levels, which explains the observed increase in glucokinase.

(a)

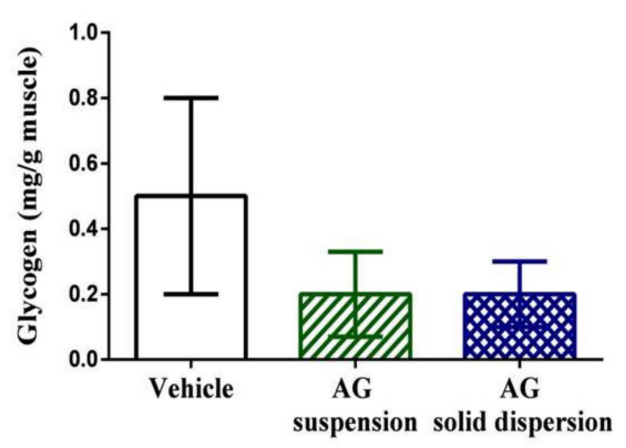

(b)

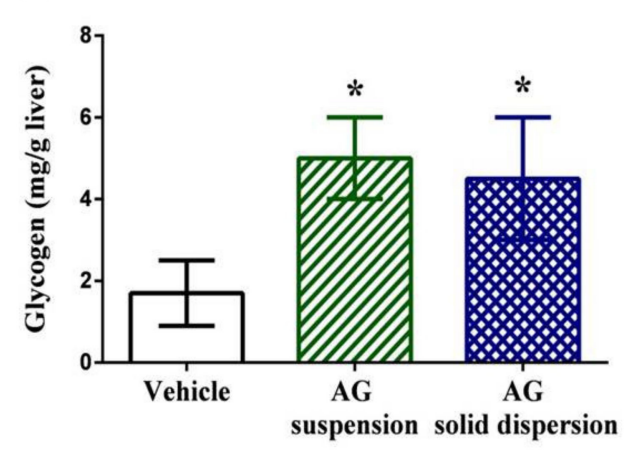

Figure 10. Effect of andrographolide (AG) on: glycogen content in: (a) muscle; and (b) liver. Data are expressed as mean \pm standard deviation ( $n=5$ for each group). * Indicates significant difference compared to vehicle group $(p<0.05)$.

\section{Materials and Methods}

\subsection{Chemicals and Reagents}

Andrographolide (purity $\geq 99.0 \%$ ), fisetin (purity $\geq 96.0 \%$ ), Tween 80, PVP K15 (Mw 15,000 g/mol), PVP K30 (Mw 40,000 g/mol), and PVP K90 (Mw 360,000 g/mol) were obtained from Tokyo Chemical Industry (Tokyo, Japan). PEG 6000 was purchased from Koch-Light Laboratories Limited (Suffolk, UK). Kolliphor EL and ethanol ( $\geq 99.8 \%$ ) were purchased from Sigma-Aldrich (St. Louis, MO, USA). Acetonitrile of chromatographic grade was purchased from Macron Fine Chemicals (Center Valley, PA, USA). Other chemicals used in the study were all of analytical grade. Pure water was obtained using the Milli-Q system (Millipore, Bedford, MA, USA).

\subsection{HPLC Analysis of Andrographolide}

The high-performance liquid chromatography (HPLC) system comprised an L-2130 pump, L-2200 auto autosampler, and L-2420 UV-VIS detector (Hitachi, Tokyo, Japan). AG was separated on a reversed-phase Luna C18 column ( $250 \mathrm{~mm} \times 4.6 \mathrm{~mm}$ i.d., $5 \mu \mathrm{m}$, Phenomenex, Torrance, CA, USA). The mobile phase consisted of acetonitrile and ammonium phosphate solution $(10 \mathrm{mM}, \mathrm{pH} 2.5$ with phosphoric acid) at a ratio of $600: 1500(v / v)$ and the flow rate was set at $1.5 \mathrm{~mL} / \mathrm{min}$. The mobile phase was filtered (0.22 $\mu \mathrm{m}$, Bedford, MA, USA) and subjected to sonication (Branson 3210, Brookfield, CT, USA) prior to use. A $20-\mu \mathrm{L}$ volume was injected into the column, and AG was monitored at $225 \mathrm{~nm}$. A stock solution of AG $(1.0 \mathrm{mg} / \mathrm{mL})$ was prepared in acetonitrile, and working standard samples were prepared using a serial dilution of the stock solution. The coefficient of determination $(\geq 0.9995)$ was used to confirm the linear range covering $1.25-100 \mu \mathrm{g} / \mathrm{mL}$.

\subsection{Preparation of Andrographolide-Loaded Solid Dispersion and Physical Mixture}

AG and polymers (PVP or PEG) combined at different ratios (e.g., 1:1, 1:3, 1:5, and 1:7, w/w) were processed using a solvent evaporation method [40]. Briefly, AG (50 mg) and polymer were dissolved in $10 \mathrm{~mL}$ ethanol, and the mixture was sonicated for $15 \mathrm{~min}$. The mixture solution was dried using rotary evaporation (N-1000SW, EYELA, Tokyo, Japan) at $50{ }^{\circ} \mathrm{C}$ under reduced pressure. The residual ethanol was removed by placing the solution in an oven at $50{ }^{\circ} \mathrm{C}$ for $24 \mathrm{~h}$. A physical mixture was prepared by mixing a corresponding amount of AG with PVP K30 and Kolliphor EL (1:7:1, w/w/w) 
using a porcelain mortar. Each formulation was sieved through a 40-mesh sieve to minimize particle size variation among samples. All formulations were kept in a glass desiccator with silica desiccant.

\subsection{Formulation Characterization}

\subsubsection{In vitro Dissolution}

The in vitro dissolution study was performed according to the procedure of a previous work [57]. The release of AG from the physical mixture and SDs were evaluated using the paddle method (SR8 PLUS dissolution test station, Hanson Research, Chatsworth, CA, USA). The $0.1 \mathrm{~N}$ hydrochloric acid solution ( $\mathrm{pH} 1.2,900 \mathrm{~mL}$ ) was used as the dissolution medium, which was maintained at $37 \pm 0.5^{\circ} \mathrm{C}$ with a stir speed of 100 revolutions per minute (rpm). The sample $(1 \mathrm{~mL})$ was collected at $0,5,10$, $15,30,45,60,90,120,150$, and $180 \mathrm{~min}$, and the dissolution fluid was maintained by supplying an equal volume of fresh $0.1 \mathrm{~N} \mathrm{HCl}$ solution after each withdrawal. The samples were centrifuged at 25 ${ }^{\circ} \mathrm{C}$ (10000 rpm for $10 \mathrm{~min}$ ), and the supernatant was transferred to the autosampler vials for HPLC analysis. Parameters, such as $\mathrm{Q}_{5 \min }, \mathrm{Q}_{120 \mathrm{~min}}$, D.E., and $\mathrm{t}_{70 \%}$, were used for evaluating the dissolution performance of the various formulations.

\subsubsection{Differential Scanning Calorimetric Analysis}

DSC assessment was conducted by weighing a 10-mg sample in an aluminum pan heated from $25^{\circ} \mathrm{C}$ to $300{ }^{\circ} \mathrm{C}$ (rate: $10^{\circ} \mathrm{C} / \mathrm{min}$ ) using a differential scanning calorimeter (Model $404 \mathrm{~F} 3$, Netzsch, Bavaria, Germany).

\subsubsection{Powder X-Ray Diffraction Analysis}

PXRD pattern of pure AG, polymer as well as the physical mixture and SD were recorded using an X-ray diffractometer (Siemens D5000, Munich, Germany). The samples were ground into a fine powder before analysis and determined over a $2 \theta$ range of $5^{\circ}-70^{\circ}$ with a scan step size of $0.1^{\circ}$ at a scan speed of $0.76 \mathrm{~s} / \mathrm{step}$.

\subsubsection{Fourier Transform Infrared Spectroscopy}

The samples were dispersed in potassium bromide using a mortar and pestle and were pressed to thin and translucent tablets. FT-IR was performed in a PerkinElmer 2000 spectrophotometer (Waltham, MA, USA), and the spectra were recorded from 4000 to $400 \mathrm{~cm}^{-1}$.

\subsection{Animals}

The protocol for animal experiments, based on the guidelines of the Animal Protection Act and A Guidebook for the Care and Use of Laboratory Animals published by the government authority and approved by the Institutional Animal Care and Use Committee of Kaohsiung Medical University Hospital (No. IACUC-105006, 22, Mar. 2017), were followed. Male Sprague-Dawley rats (weight: $200 \pm 20 \mathrm{~g}$ ) were obtained from the BioLASCO company (Taipei, Taiwan). Animals were specifically pathogen-free and were housed with a 12-h light-dark cycle and fed for $24 \mathrm{~h}$ with food and water.

\subsection{Ex vivo Permeability}

The permeability assessment for AG was conducted using the everted gut sac method [58]. Briefly, reverted intestine segments (duodenum, jejunum, and ileum) filled with Tyrode's solution were transferred into flasks containing Tyrode's solution. AG and the optimized AG-loaded SD were separately added to the flasks to achieve a concentration of $50 \mu \mathrm{g} / \mathrm{mL}$ of AG. Tyrode's solution with each segment sample was collected after shaking in a water bath for $1 \mathrm{~h}$, and AG content within was analyzed using the HPLC method. 


\subsection{Oral Bioavailability Evaluation}

Two groups of male Sprague-Dawley rats ( $n=5$ for each) were involved in this study, and repeated blood sampling was achieved through a jugular vein catheterization model [59]. Both AG powder and the optimized AG-loaded SD were suspended in pure water. One group received AG (dose: 300 $\mathrm{mg} / \mathrm{kg}$ ), and the other group received AG-loaded SD (dose: $100 \mathrm{mg} / \mathrm{kg}$ ). Blood samples (300 $\mu \mathrm{L}$ ) were taken using a catheter at $0.083,0.25,0.5,0.75,1,1.5,2,2.5,3,4,5,6$, and $8 \mathrm{~h}$ after AG administration. For the HPLC analysis of rat plasma samples, AG was extracted and determined according to the procedure of our previous paper [11]. Oral bioavailability was calculated by comparing the AUC between AG suspension and AG-loaded SD after dosage normalization.

\subsection{Anti-Fatigue Evaluation}

The anti-fatigue evaluation for AG was conducted using swimming exercises according to our previous report [30] with slight modification. Three groups of male Sprague-Dawley rats $(n=5$ for each) were used in this experiment and were given three different pretreatments for 3 days. The first group was orally given water and served as a vehicle group; the second group was orally given AG suspension $(100 \mathrm{mg} / \mathrm{kg})$ and served as the control group; and the third group was given AG-loaded $\mathrm{SD}(100 \mathrm{mg} / \mathrm{kg})$. After a 3-day pretreatment with AG-loaded SD, the rats were individually placed in water containers ( $40 \mathrm{~cm}$ long, $40 \mathrm{~cm}$ wide, and $50 \mathrm{~cm}$ high) with water at a depth of $30 \mathrm{~cm}$ kept at $27 \pm$ $1{ }^{\circ} \mathrm{C}$ to determine lactate production and clearance ratios, forelimb grip strength, blood biochemical variables, swimming exercise performance, and tissue glycogen levels.

For the exhaustion exercise test, weights equivalent to $15 \%$ of body weight were attached to the rats. Swimming time from beginning to exhaustion was recorded as the endurance of each rat. Time for exhaustion was defined as time taken for rats to experience a loss of movement coordination and inability to return to the surface within $7 \mathrm{~s}$. For lactate production and clearance, rats were loaded with constant weights corresponding to $5 \%$ of individual body weight and were allowed to swim for $10 \mathrm{~min}$. Lactate Pro ${ }^{\mathrm{TM}} 2$ (LT-1730, Kyoto, Japan) was used to analyze pre-swimming and post-swimming blood lactate levels half an hour before and after swimming. The blood lactate production and clearance ratios were calculated using the following equations: Lactate production ratio $=\left(\right.$ Lactate $_{\text {post-swimming }}-$ Lactate $\left._{\text {pre-swimming }}\right) /$ Lactate pre-swimming; $_{\text {Lactate }}$ clearance ratio $=\left(\right.$ Lactate $_{\text {post- swimming }}-$ Lactate $\left._{30 \text { min later after post-swimming }}\right) /$ Lactate post-swimming. $_{\text {For }}$ measurement of forelimb grip strength in rats, a low-force testing system (BioSeb, Chaville, France) was utilized in this test. The effects of $\mathrm{AG}$ on $\mathrm{NH}_{3}, \mathrm{BUN}, \mathrm{CPK}$, and glucose were evaluated after a 15 -min swimming exercise with $5 \%$ of individual body weight-loading. All blood biochemical levels were measured using an autoanalyzer (Beckman Coulter DXC800, Brea, CA, USA). For tissue glycogen determination, skeletal muscles and liver were used to investigate changes in their glycogen content after AG-loaded SD administration. The method used to measure and analyze glycogen content was the same as described in our previous studies [30].

\subsection{Data Analysis}

The experimental results are presented as mean \pm standard deviation values. The pharmacokinetic parameters were derived from a noncompartmental model analysis [60,61]. SPSS v14.0 (SPSS Inc., Chicago, IL, USA) was used to conduct analysis of variance, and multiple comparisons of variance were evaluated using the Scheffe post hoc test. A $p$ value of $<0.05$ was considered significantly difference.

\section{Conclusions}

In this study, AG-loaded SD was successfully developed to improve the dissolution profile of AG and increase its oral absorption compared with free AG powder. The results suggest that the dissolution rate of AG from SD depended on the concentration of the carrier. Moreover, PVP generally exhibited quicker release than SD made of PEG 6000. PVP K30 inhibited the crystallization of the drug, resulting 
in the amorphous form of the drug in SD. PXRD and DSC results confirmed the amorphous state of the drug in SD. The pharmacokinetic analysis conducted on the rats indicated that the optimized AG-loaded SD (AG/PVP K30/Kolliphor EL = 1:7:1, w/w/w) increased the relative bioavailability of AG by approximately three-fold. Furthermore, we confirmed that the optimized SD could increase the swimming time to exhaustion by 1.7 -fold, and positively modulate fatigue-related parameters, including ammonia values and liver glycogen levels. Thus, AG-loaded SD not only provides a promising strategy for improving AG oral bioavailability but also protection against physical fatigue.

Author Contributions: C.-C.Y., Y.-K.L., C.-P.C., M.-C.H., and Y.-T.W. participated in the study design and drafting and revising of the manuscript. C.-C.Y., Y.-K.L., and C.-P.C. conducted the experiments. C.-C.Y. and Y.-T.W. contributed to the analysis and interpretation of data. All authors read and approved the final manuscript.

Funding: This study was provided in part by MOST 106-2410-H-037-007-MY3 and MOST 108-2410-H-037-021 from the Ministry of Science and Technology, Taiwan, R.O.C.; and in part by KMU-TC108A03-8 and KMU-TC108A03-9 from Drug Development and Value Creation Research Center, Kaohsiung Medical University, Taiwan, R.O.C.

Acknowledgments: The authors appreciate the Instrumentation Center, National Taiwan University for helping differential scanning calorimetric analysis of solid dispersion samples.

Conflicts of Interest: The authors declare no conflict of interest.

\section{References}

1. Chao, W.W.; Lin, B.F. Isolation and identification of bioactive compounds in Andrographis paniculata (chuanxinlian). Chin. Med. 2010, 5, 17. [CrossRef] [PubMed]

2. Tan, W.D.; Liao, W.; Zhou, S.; Wong, W.F. Is there a future for andrographolide to be an anti-inflammatory drug? Deciphering its major mechanisms of action. Biochem. Pharmacol. 2017, 139, 71-81. [CrossRef] [PubMed]

3. Mussard, E.; Cesaro, A.; Lespessailles, E.; Legrain, B.; Berteina-Raboin, S.; Toumi, H. Andrographolide, A Natural Antioxidant: An Update. Antioxidants 2019, 8, 571. [CrossRef] [PubMed]

4. Dai, Y.; Chen, S.R.; Chai, L.; Zhao, J.; Wang, Y.; Wang, Y. Overview of pharmacological activities of Andrographis paniculata and its major compound andrographolide. Crit. Rev. Food Sci. Nutr. 2019, 59 (Suppl. S1), S17-S29. [CrossRef]

5. Fan, L.; Feng, Y.; Chen, G.C.; Qin, L.Q.; Fu, C.L.; Chen, L.H. Effects of coenzyme Q10 supplementation on inflammatory markers: A systematic review and meta-analysis of randomized controlled trials. Pharmacol. Res. 2017, 119, 128-136. [CrossRef] [PubMed]

6. Castro-Marrero, J.; Sáez-Francàs, N.; Segundo, M.J.; Calvo, N.; Faro, M.; Aliste, L.; De Fernández Sevilla, T.; Alegre, J. Effect of coenzyme Q10 plus nicotinamide adenine dinucleotide supplementation on maximum heart rate after exercise testing in chronic fatigue syndrome-A randomized, controlled, double-blind trial. Clin. Nutr. 2016, 35, 826-834. [CrossRef]

7. Simioni, C.; Zauli, G.; Martelli, A.M.; Vitale, M.; Sacchetti, G.; Gonelli, A.; Neri, L.M. Oxidative stress: Role of physical exercise and antioxidant nutraceuticals in adulthood and aging. Oncotarget 2018, 9, 17181-17198. [CrossRef]

8. Huang, W.C.; Chiu, W.C.; Chuang, H.L.; Tang, D.W.; Lee, Z.M.; Wei, L.; Huang, C.C. Effect of curcumin supplementation on physiological fatigue and physical performance in mice. Nutrients 2015, 7, 905-921. [CrossRef]

9. Bertoglio, J.C.; Baumgartner, M.; Palma, R.; Ciampi, E.; Carcamo, C.; Cáceres, D.D.; Acosta-Jamett, G.; Hancke, J.L.; Burgos, R.A. Andrographis paniculata decreases fatigue in patients with relapsing-remitting multiple sclerosis: A 12-month double-blind placebo-controlled pilot study. BMC Neurol. 2016, 16, 77-84. [CrossRef]

10. Chen, H.W.; Huang, C.S.; Li, C.C.; Lin, A.H.; Huang, Y.J.; Wang, T.S.; Yao, H.T.; Lii, C.K. Bioavailability of andrographolide and protection against carbon tetrachloride-induced oxidative damage in rats. Toxicol. Appl. Pharmacol. 2014, 280, 1-9. [CrossRef]

11. Yen, C.C.; Chen, Y.C.; Wu, M.T.; Wang, C.C.; Wu, Y.T. Nanoemulsion as a strategy for improving the oral bioavailability and anti-inflammatory activity of andrographolide. Int. J. Nanomed. 2018, 13, 669-680. [CrossRef] [PubMed] 
12. Panossian, A.; Hovhannisyan, A.; Mamikonyan, G.; Abrahamian, H.; Hambardzumyan, E.; Gabrielian, E.; Goukasova, G.; Wikman, G.; Wagner, H. Pharmacokinetic and oral bioavailability of andrographolide from Andrographis paniculata fixed combination kan jang in rats and human. Phytomedicine 2000, 7, 351-364. [CrossRef]

13. Lee, S.Y; Abdullah, L.C.; Rahman, R.A.; Abas, F.; Chong, G.H. Role of polymers as crystal growth inhibitors in coprecipitation via solution-enhanced dispersion by supercritical fluids (seds) to improve andrographolide dissolution from standardized Andrographis paniculata extract. J. Drug Deliv. Sci. Technol. 2019, 50, 145-154. [CrossRef]

14. Ren, K.; Zhang, Z.; Li, Y.; Liu, J.; Zhao, D.; Zhao, Y.; Gong, T. Physicochemical characteristics and oral bioavailability of andrographolide complexed with hydroxypropyl-beta-cyclodextrin. Pharmazie 2009, 64, 515-520. [PubMed]

15. Ye, L.; Wang, T.; Tang, L.; Liu, W.; Yang, Z.; Zhou, J.; Zheng, Z.; Cai, Z.; Hu, M.; Liu, Z. Poor oral bioavailability of a promising anticancer agent andrographolide is due to extensive metabolism and efflux by P-glycoprotein. J. Pharm. Sci. 2011, 100, 5007-5017. [CrossRef] [PubMed]

16. Bothiraja, C.; Shinde, M.B.; Rajalakshmi, S.; Pawar, A.P. Evaluation of molecular pharmaceutical and in-vivo properties of spray-dried isolated andrographolide-PVP. J. Pharm. Pharmacol. 2009, 61, 1465-1472. [CrossRef]

17. Zhao, G.; Zeng, Q.; Zhang, S.; Zhong, Y.; Wang, C.; Chen, Y.; Qu, L.; Liao, Z. Effect of Carrier Lipophilicity and Preparation Method on the Properties of Andrographolide-Solid Dispersion. Pharmaceutics 2019, 11, 74. [CrossRef]

18. Zhang, D.; Lin, J.; Zhang, F.; Han, X.; Han, L.; Yang, M.; Zou, W. Preparation and evaluation of andrographolide solid dispersion vectored by silicon dioxide. Pharmacogn. Mag. 2016, 12, S245-S252.

19. Ma, Y.; Yang, Y.; Xie, J.; Xu, J.; Yue, P.; Yang, M. Novel nanocrystal-based solid dispersion with high drug loading, enhanced dissolution, and bioavailability of andrographolide. Int. J. Nanomed. 2018, 13, 3763-3779. [CrossRef]

20. Xu, J.; Ma, Y.; Xie, Y.; Chen, Y.; Liu, Y.; Yue, P.; Yang, M. Design and evaluation of novel solid self-nanodispersion delivery system for andrographolide. AAPS PharmSciTech 2017, 18, 1572-1584. [CrossRef]

21. Jain, P.K.; Khurana, N.; Pounikar, Y.; Gajbhiye, A.; Kharya, M.D. Enhancement of absorption and hepatoprotective potential through soya-phosphatidylcholine-andrographolide vesicular system. J. Liposome Res. 2013, 23, 110-118. [CrossRef] [PubMed]

22. Tu, Y.S.; Sun, D.M.; Zhang, J.J.; Jiang, Z.Q.; Chen, Y.X.; Zeng, X.H.; Huang, D.E.; Yao, N. Preparation and characterisation of andrographolide niosomes and its anti-hepatocellular carcinoma activity. J. Microencapsul. 2014, 31, 307-316. [CrossRef] [PubMed]

23. Parveen, R.; Ahmad, F.J.; Iqbal, Z.; Ahmad, S. Effect of andrographolide solid lipid nanoparticles (SLNs) on breast cancer. Planta Med. 2013, 79, P105. [CrossRef]

24. Chellampillai, B.; Pawar, A.P. Improved bioavailability of orally administered andrographolide from pH-sensitive nanoparticles. Eur. Drug Metab. Pharmacokinet. 2011, 35, 123-129. [CrossRef] [PubMed]

25. Yang, T.; Sheng, H.H.; Feng, N.P.; Wei, H.; Wang, Z.T.; Wang, C.H. Preparation of and rographolide-loaded solid lipid nanoparticles and their in vitro and in vivo evaluations: Characteristics, release, absorption, transports, pharmacokinetics, and antihyperlipidemic activity. J. Pharm. Sci. 2013, 102, 4414-4425. [CrossRef] [PubMed]

26. Sermkaew, N.; Ketjinda, W.; Boonme, P.; Phadoongsombut, N.; Wiwattanapatapee, R. Liquid and solid self-microemulsifying drug delivery systems for improving the oral bioavailability of andrographolide from a crude extract of Andrographis paniculata. Eur. J. Pharm. Sci. 2013, 50, 459-466. [CrossRef]

27. Leuner, C.; Dressman, J. Improving drug solubility for oral delivery using solid dispersions. Eur. J. Pharm. Biopharm. 2000, 50, 47-60. [CrossRef]

28. Fitriani, L.; Rismawati, E.; Umar, S.; Zaini, E. Solid Dispersion of Usnic Acid-PVP K30 and Evaluation of Antioxidant Activity. Rasayan J. Chem. 2018, 11, 1643-1648. [CrossRef]

29. Nadal, J.M.; Gomes, M.L.S.; Borsato, D.M.; Almeida, M.A.; Barboza, F.M.; Zawadzki, S.F.; Farago, P.V.; Zanin, S.M.W. Spray-dried solid dispersions containing ferulic acid: Comparative analysis of three carriers, in vitro dissolution, antioxidant potential and in vivo anti-platelet effect. Drug Dev. Ind. Pharm. 2016, 42, 1813-1824. [CrossRef]

30. Yen, C.C.; Chang, C.W.; Hsu, M.C.; Wu, Y.T. Self-nanoemulsifying drug delivery system for resveratrol: Enhanced oral bioavailability and reduced physical fatigue in rats. Int. J. Mol. Sci. 2017, 18, 1853. [CrossRef] 
31. Ghaderi, R.; Artursson, P.; Carlfors, J. Preparation of biodegradable microparticles using solution-enhanced dispersion by supercritical fluids (seds). Pharm. Res. 1999, 16, 676-681. [CrossRef] [PubMed]

32. Franco, M.; Trapani, G.; Latrofa, A.; Tullio, C.; Provenzano, M.R.; Serra, M.; Muggironi, M.; Biggio, G.; Liso, G. Dissolution properties and anticonvulsant activity of phenytoin-polyethylene glycol 6000 and -polyvinylpyrrolidone K-30 solid dispersions. Int. J. Pharm. 2001, 225, 63-73. [CrossRef]

33. Hilton, J.E.; Summers, M.P. The effect of wetting agents on the dissolution of indomethacin solid dispersion systems. Int. J. Pharm. 1986, 31, 157-164. [CrossRef]

34. Mura, P.; Moyano, J.R.; Gonzalez-Rodriguez, M.L.; Rabasco-Alvarez, A.M.; Cirri, M.; Maestrelli, F. Characterization and dissolution properties of ketoprofen in binary and ternary solid dispersions with polyethylene glycol and surfactants. Drug Dev. Ind. Pharm. 2005, 31, 425-434. [CrossRef] [PubMed]

35. Okonogi, S.; Puttipipatkhachorn, S. Dissolution improvement of high drug-loaded solid dispersion. AAPS PharmSciTech 2006, 7, E148-E153. [CrossRef] [PubMed]

36. Vasconcelos, T.; Sarmento, B.; Costa, P. Solid dispersions as strategy to improve oral bioavailability of poor water soluble drugs. Drug Discov. Today 2007, 12, 1068-1075. [CrossRef]

37. Maiti, K.; Mukherjee, K.; Murugan, V.; Saha, B.P.; Mukherjee, P.K. Enhancing bioavailability and hepatoprotective activity of andrographolide from Andrographis paniculata, a well-known medicinal food, through its herbosome. J. Sci. Food Agric. 2010, 90, 43-51. [CrossRef]

38. Frizon, F.; De Oliveira Eloy, J.; Donaduzzi, C.M.; Mitsui, M.L.; Marchetti, J.M. Dissolution rate enhancement of loratadine in polyvinylpyrrolidone K-30 solid dispersions by solvent methods. Powder Technol. 2013, 235, 532-539. [CrossRef]

39. Mendes, C.; Buttchevitz, A.; Kruger, J.H.; Caon, T.; De Oliveira Benedet, P.; Lemos-Senna, E.; Silva, M.A.S. Self-nanoemulsified drug delivery system of hydrochlorothiazide for increasing dissolution rate and diuretic activity. AAPS PharmSciTech 2017, 18, 2494-2504. [CrossRef]

40. Mistry, P.; Mohapatra, S.; Gopinath, T.; Vogt, F.G.; Suryanarayanan, R. Role of the strength of drug-polymer interactions on the molecular mobility and crystallization inhibition in ketoconazole solid dispersions. Mol. Pharm. 2015, 12, 3339-3350. [CrossRef]

41. Shono, Y.; Nishihara, H.; Matsuda, Y.; Furukawa, S.; Okada, N.; Fujita, T.; Yamamoto, A. Modulation of intestinal P-glycoprotein function by cremophor el and other surfactants by an in vitro diffusion chamber method using the isolated rat intestinal membranes. J. Pharm. Sci. 2004, 93, 877-885. [CrossRef] [PubMed]

42. Evans, W.J.; Lambert, C.P. Physiological basis of fatigue. Am. J. Phys. Med. Rehabil. 2007, 86, S29-S46. [CrossRef] [PubMed]

43. Coombes, J.S.; Rowell, B.; Dodd, S.L.; Demirel, H.A.; Naito, H.; Shanely, A.R.; Powers, S.K. Effects of vitamin e deficiency on fatigue and muscle contractile properties. Eur. J. Appl. Physiol. 2002, 87, 272-277. [CrossRef]

44. Gladden, L.B. Lactate metabolism: A new paradigm for the third millennium. J. Physiol. 2004, 558, 5-30. [CrossRef] [PubMed]

45. Ni, W.; Gao, T.; Wang, H.; Du, Y.; Li, J.; Li, C.; Wei, L.; Bi, H. Anti-fatigue activity of polysaccharides from the fruits of four tibetan plateau indigenous medicinal plants. J. Ethnopharmacol. 2013, 150, 529-535. [CrossRef]

46. Sanchez-Medina, L.; González-Badillo, J.J. Velocity loss as an indicator of neuromuscular fatigue during resistance training. Med. Sci. Sports Exerc. 2011, 43, 1725-1734. [CrossRef]

47. Banister, E.W.; Cameron, B.J. Exercise-induced hyperammonemia: Peripheral and central effects. Int. J. Sports Med. 1990, 11, 129-142. [CrossRef]

48. Jing, L.; Cui, G.; Feng, Q.; Xiao, Y. Orthogonal test design for optimization of the extraction of polysaccharides from lycium barbarum and evaluation of its anti-athletic fatigue activity. J. Med. Plants Res. 2009, 3, $433-437$.

49. Horng, C.T.; Huang, J.K.; Wang, H.Y.; Huang, C.C.; Chen, F.A. Antioxidant and antifatigue activities of Polygonatum Alte-lobatum Hayata rhizomes in rats. Nutrients 2014, 6, 5327-5337. [CrossRef]

50. Warren, G.L.; Ingalls, C.P.; Lowe, D.A.; Armstrong, R.B. Excitation-contraction uncoupling: Major role in contraction-induced muscle injury. Exerc. Sport Sci. Rev. 2001, 29, 82-87.

51. Suh, S.H.; Paik, I.Y.; Jacobs, K. Regulation of blood glucose homeostasis during prolonged exercise. Mol. Cells 2007, 23, 272-279. [PubMed]

52. McClung, J.M.; DeRuisseau, K.C.; Whidden, M.A.; Van Remmen, H.; Richardson, A.; Song, W.; Vrabas, I.S.; Powers, S.K. Overexpression of antioxidant enzymes in diaphragm muscle does not alter contraction-induced fatigue or recovery. Exp. Physiol. 2010, 95, 222-231. [CrossRef] [PubMed] 
53. Wu, R.E.; Huang, W.C.; Liao, C.C.; Chang, Y.K.; Kan, N.W.; Huang, C.C. Resveratrol protects against physical fatigue and improves exercise performance in mice. Molecules 2013, 18, 4689-4702. [CrossRef] [PubMed]

54. Norenberg, M.D. Oxidative and nitrosative stress in ammonia neurotoxicity. Hepatology 2003, 37, $245-248$. [CrossRef] [PubMed]

55. Sahlin, K.; Tonkonogi, M.; Söderlund, K. Energy supply and muscle fatigue in humans. Acta Physiol. Scand. 1998, 162, 261-266. [CrossRef]

56. Subramanian, R.; Asmawi, M.Z.; Sadikun, A. Effect of andrographolide and ethanol extract of Andrographis paniculata on liver glycolytic, gluconeogenic, and lipogenic enzymes in a type 2 diabetic rat model. Pharm. Biol. 2008, 46, 772-780. [CrossRef]

57. Chang, C.W.; Wang, C.Y.; Wu, Y.T.; Hsu, M.C. Enhanced solubility, dissolution, and absorption of lycopene by a solid dispersion technique: The dripping pill delivery system. Powder Technol. 2016, 301, 641-648. [CrossRef]

58. Gurunath, S.; Nanjwade, B.K.; Patila, P.A. Enhanced solubility and intestinal absorption of candesartan cilexetil solid dispersions using everted rat intestinal sacs. Saudi Pharm. J. 2014, 22, 246-257. [CrossRef]

59. Thrivikraman, K.V.; Huot, R.L.; Plotsky, P.M. Jugular vein catheterization for repeated blood sampling in the unrestrained conscious rat. Brain Res. Protoc. 2002, 10, 84-94. [CrossRef]

60. Gibaldi, M.; Perrier, D. Noncompartmental analysis based on statistical moment theory. Pharmacokinetics 1982, 2, 409-417.

61. Barron, M.G.; Stehly, G.R.; Hayton, W.L. Pharmacokinetic modeling in aquatic animals I. Models and concepts. Aquat. Toxicol. 1990, 17, 187-212. [CrossRef]

(C) 2020 by the authors. Licensee MDPI, Basel, Switzerland. This article is an open access article distributed under the terms and conditions of the Creative Commons Attribution (CC BY) license (http://creativecommons.org/licenses/by/4.0/). 